\title{
EFEITO DO ARMAZENAMENTO DA CALDA NA EFICÁCIA DE HERBICIDAS APLICADOS EM: I. PÓS-EMERGÊNCIA ${ }^{1,2}$
}

\author{
HAMILTON H. RAMOS ${ }^{3}$ e JULIO C. DURIGAN ${ }^{4}$
}

\section{RESUMO}

Diferentes tipos de pulverizadores são utilizados para a aplicação de herbicidas sendo que, em pequenas propriedades, é comum, por questões econômicas, a adaptação de barras ou pistolas manuais a tanques de grande capacidade. Por outro lado, em grandes propriedades, é crescente a tendência da substituição do sistema tradicional de reabastecimento dos pulverizadores pelo sistema de calda pronta. Em ambos os casos, pode haver a necessidade de um armazenamento prolongado nos tanques ou no veículo reabastecedor, principalmente na ocorrência de períodos prolongados de chuva. Torna-se, portanto, importante a determinação de períodos de tempo pelos quais as caldas de herbicidas possam ser armazenadas, sem que haja prejuízo à eficácia dos mesmos. $\mathrm{O}$ presente trabalho estudou os efeitos do tempo de armazenamento da calda sobre a eficácia de herbicidas aplicados em pósemergência. $O$ experimento foi instalado no delineamento experimental de blocos ao acaso, com três repetições, no ano agrícola de 91/92, em Área da Fazenda Experimental da Faculdade de Ciências Agrárias e Veterinárias da UNESP, município de Jaboticabal, Estado de São Paulo, Brasil. Avaliou-se as formulações comerciais de glyphosate, mistura pronta de glyphosate $+2,4-\mathrm{D}$, MSMA e paraquat com $00,05,10,15,20,25$ e 30 dias de armazenamento da calda, além de uma testemunha, onde não se efetuou a aplicação de herbicidas. Foram realizadas avaliações visuais de controle, geral e por espécie, aos 15, 31 e 46 dias após a aplicação e os resultados obtidos mostram que nenhum dos períodos de armazenamento testados interferiu significativamente na eficiência dos herbicidas (teste de $\mathrm{F}$ a 5\%), independente do produto utilizado e da época de avaliação. Portanto, conclui-se que as caldas dos herbicidas testados puderam ser utilizadas normalmente, quando armazenadas por até 30 dias.

Palavras chave: glyphosate, 2,4-D, paraquat, MSMA.

\section{ABSTRACT}

\section{Effect of storage time of diluted herbicides mix on their effectiveness: I. pós-emergency herbicides}

Different types of sprayers are used in farm practice. In small farms it is getting more economical to couple spraying booms and manual spraying lances to large volume tanks. In large farms the trend is to replace the traditional system by the ready diluted mix system. In both cases a prolonged storing time of the mix in tanks or refilling vehicle, especially in rainy periods of the year is required. So, it is important to determine how long the storage time may be without causing the effectiveness of the diluted mix to decrease. That is what this paper is related to. A random block design trial was carried out during the 1991/92 crop season, at the Experimental Station of the Agronomy College of UNESP, in Jaboticabal, São Paulo, Brazil. Diluted mixes of

\footnotetext{
${ }^{1}$ Recebido para publicação em 17/03/95 e na forma revisada em 23/12/98.

2 Parte da dissertação do primeiro autor apresentada à FCAVJ/UNESP para obtenção do título de Mestre em Agronomia.

${ }^{3}$ Seção de Máquinas Implantadoras de Culturas e Aplicadoras de Defensivos, Instituto Agronômico (IAC). C.P. 26, CEP 13201 -970, Jundiai/SP.

${ }^{4}$ Dept $^{\circ}$ de Defesa Fitossanitária, FCVAJ/UNESP. CEP 14.870-000, Jaboticabal/SP.
} 
commercial formulation of glyphosate, MSMA and paraquat beyond a ready-for-use glyphosate $+2,4-\mathrm{D}$ amine mix were evaluted at 00, 05, 10, $15,20,25$ and 30 days of storage. A testimony plot was not spraied. Visual control evaluations, both general and by species were perfomed at 15,31 and 46 days after spraying. The results showed no influence of storage periods on herbicides efficiencies (Tukey, 5\%) no matter independent of the commercial product and time of evaluation. One concluded that the diluted mixes can be normally used provided the storage time doesn't exceed 30 days.

Key words: glyphosate, 2,4-D, paraquat, MSMA.

\section{INTRODUÇÃO}

Diferentes tipos de pulverizadores são utilizados para a aplicação de herbicidas em pomares cítricos. $\mathrm{O}$ mais comum em pequenas e médias propriedades, por questões econômicas, é a adaptação de barras ou pistolas manuais aos equipamentos para aplicação de inseticidas e acaricidas. No entanto, devido a alta capacidade do tanque (normalmente $2000 \mathrm{l}$ ) e ao volume de calda bem menor utilizado no controle de plantas daninhas em relação ao controle das outras pragas citadas, é comum se demorar 12 horas ou mais para a aplicação de um tanque de calda. Este tempo pode ser ainda maior se, durante a aplicação, iniciar-se um período chuvoso.

Por outro lado, em grandes propriedades, onde há normalmente longa distância entre as áreas de aplicação e as fontes de água, encarecendo sobremaneira a operação, a tendência natural é a substituição do sistema convencional de reabastecimento dos pulverizadores (que consiste em preparar a calda para cada tanque no local de aplicação) pelo sistema de "calda pronta", que consiste em preparar a calda diretamente sobre um veículo reabastecedor. Este último sistema, segundo Matuo (1985) e Ozeki et al. (sem data), permite ainda menor extravio e desperdício de produtos, menor possibilidade de erro na dosificação, menor exposição dos manipuladores e facilita a operação de reabastecimento, uma vez que possibilita o reenchimento do tanque do pulverizador a qualquer momento, evitando frequentes traslados pelo esgotamento no meio do talhão ou no carreador oposto ao do veículo reabastecedor. No entanto, a adoção do sistema de "calda pronta" também pode levar à necessidade de um armazenamento prolongado da calda nos

\section{tanques ou no veículo reabastecedor, principalmente na ocorrência de períodos prolongados de chuva.}

Os estudos sobre alterações físicoquímicas em herbicidas devido ao armazenamento quase sempre se referem ao produto concentrado ou a sua degradação no ambiente após a aplicação da calda, porém quase nenhuma atenção tem sido dada a degradação da calda armazenada.

Segundo Friestad (1978) citado por Brønstad \& Friestad (1985) o glyphosate puro é estável por vários anos a temperatura ambiente, quando dissolvido em água destilada ou em ácido clorídrico $1 \mathrm{~N}$. Caldas com o produto formulado, armazenadas em frascos de vidro à temperatura ambiente, não variaram visivelmente em 7 meses. A tendência de decomposição hidrolítica é também baixa ou inexistente. Assim, a concentração de soluções padrões de ácido clorídrico $0,1 \mathrm{~N}$ ou hidróxido de amônio $0,1 \mathrm{~N}$ de 11 a $10 \mathrm{ml}$ sobre uma chapa quente, não resultou em perda de glyphosate.

Bowmer et al.(1986) citam que apesar de se esperar que, num meio aquático, a adsorção do glyphosate pelos sedimentos e sólidos em suspensão influenciasse o movimento do mesmo para fora da zona de aplicação e atenuasse sua fitotoxicidade, os resultados de dois experimentos por eles montados mostraram que somente uma menor proporção do glyphosate foi adsorvido pelos sólidos existentes em suspensão, na água turva de irrigação. Contudo, quando o glyphosate foi pulverizado sobre os sedimentos expostos, após a drenagem do canal de irrigação, menos de 7\% do glyphosate aplicado foi posteriormente eludido.

Lund-Høie \& Friestad (1986) estudaram a fotodegradação do herbicida glyphosate na água, e verificaram que este foi enormemente degradado 
pela luz UV mas não pela luz com longo comprimento de onda. A degradação também foi maior em água pura do que em água poluída, provavelmente porque nesta última as impurezas da água reduziram a penetração da luz UV. A suspensão de argila na água pura prejudicou ainda mais a penetração da luz UV e a degradação fotolítica aparentemente superou os efeitos combinados de fotólise e adsorção da água com argila em suspensão. Após nove semanas, cerca de 90\% do herbicida tinha sido dissipado da água, dos quais, cerca de dois-terços foram removidos através da decantação da argila.

Rueppel et al. (1977) também estudaram a degradação de soluções de glyphosate em um fotoreator. e observaram que menos de $2 \%$ do composto $\mathrm{N}$-fosfono- ${ }^{14} \mathrm{C}$-metil desapareceu como produto volátil de degradação após irradiação em um reator de Crosby por um período equivalente a 16 dias com 8 horas de luz do sol. Nenhuma alteração foi observada também na composição da solução aquosa com relação ao seu conteúdo de glyphosate, ácido amino-metil-fosfonico (AMPA) e $\mathrm{N}$-metil derivado mais tardio. Em vista da degradação microbiana consideravelmente rápida observada em estudos anteriores, eles concluiram que a fotodecomposição exerceria uma função muito menor na decomposição ambiental do glyphosate. No entanto, segundo Frazier em comunicação pessoal a Brønstad \& Friestad (1985), quando em sequência a estes estudos a água deionizada, estéril, foi substituida por água natural, estéril, a foto-irrigação de $1 \mathrm{ppm}$ de solução resultou em $18,4 \%$ e $86,7 \%$ de transformação para AMPA em 1 e 14 dias, respectivamente. Os controles escuros mostraram glyphosate como sendo estável. Este trabalho posterior sugeriu que o glyphosate é altamente instável em águas naturais e acreditou-se que esta foto-instabilidade seja catalisada por cálcio e outros íons metálicos.

Almeida \& Rodrigues (1985) citam que os principais microrganismos que degradam o 2,4-D no solo são bactérias como Pseudomonas sp, Achromobacter sp, Arthrobacter sp, e actnomicetos como Neocardia sp e Streptomyces viridochromogenes. Na degradação do 2,4-D por Arthrobacter sp e Pseudomonas sp há a formação de ácido succínico e possivelmente de ácido acético. São poucas as perdas por fotodecomposição e a volatilidade é considerada baixa nas formulações em sais de amina e alta nas de éster. Em baixas doses o 2,4-D decompõem-se em 1 a 4 semanas em solos argilosos e clima quente sendo que, nos solos secos e frios, esta decomposição é consideravelmente reduzida.

Com relação à degradação do paraquat, Almeida \& Rodrigues (1985) citam que alguns microrganismos conseguem degradá-lo, e dentre eles destaca-se uma levedura do gênero Lipomyces que pode decompor até $20 \mathrm{ppm}$ do produto em poucos dias. Podem ocorrer perdas de paraquat por fotodecomposição nas superfícies das folhas ou sobre vegetação morta e em decomposição. Em solução, o paraquat está sujeito à hidrólise na presença de substâncias alcalinas.

Alguns fungos, diversos actinomicetos e algumas bactérias, segundo Almeida \& Rodrigues (1985), atuam no processo degradativo do MSMA no solo, resultando em $\mathrm{CO}_{2}$ e arsenato. Perdas por fotodecomposição e/ou volatilização não são significativas. Não é recomendada a sua mistura com produtos alcalinos.

O desconhecimento de informações sobre a degradação da calda armazenada faz com que alguns agricultores, por medo de um resultado negativo, ou aumentem o volume de aplicação ou até descartem a calda, após 24 ou 48 horas de armazenamento. Torna-se, portanto, importante a determinação de períodos de tempo pelos quais as caldas de herbicidas possam ser armazenadas, sem que haja prejuízo à eficácia dos mesmos e, consequentemente, sem resultar em prejuízos ao agricultor.

O presente trabalho foi desenvolvido com o objetivo de se estudar a influência do tempo de armazenamento da calda sobre a eficácia de alguns herbicidas aplicados em pós-emergência.

\section{MATERIAL E MÉTODOS}

O experimento foi montado no pomar da Fazenda Experimental da Faculdade de Ciências 
Agrárias e Veterinárias "Campus" de Jaboticabal da Universidade Estadual Paulista (FCAVJ UNESP), localizado na latitude de $21^{\circ} 15^{\prime} 22^{\prime \prime S}$ e longitude de $48^{\circ} 18^{\prime} 58^{\prime \prime}$ 'WGr. O clima da região, segundo a Classificação de Köppen, é o Cwa, subtropical com inverno relativamente seco. A precipitação média anual é de $1.400 \mathrm{~mm}$ e a do mês mais seco é de $13,9 \mathrm{~mm}$. A temperatura média anual é de aproximadamente $22^{\circ} \mathrm{C}$ e a do mês mais frio é inferior a $16^{\circ} \mathrm{C}$.

$\mathrm{O}$ delineamento experimental utilizado foi o de blocos ao acaso com 29 tratamentos, em esquema fatorial cujos fatores foram quatro herbicidas combinados com sete épocas de armazenamento da calda, além da testemunha sem herbicidas, repetidos três vezes. Utilizaram-se parcelas de 4,0 × 6,0 m, perfazendo a área total de $24,0 \mathrm{~m}^{2}$, demarcadas nas entrelinhas de um pomar cítrico, deixando-se uma faixa de $0,5 \mathrm{~m}$ nas extremidades de cada parcela como bordadura. As principais plantas daninhas existentes na área experimental, que receberam a aplicação dos herbicidas, foram capim-colonião (Panicum maximum Jacq.), capim-marmelada (Brachiaria plantaginea (Link) Hitch.), capim-amargoso (Digitaria insularis (L.) Mez ex Ekman), losnabranca (Parthenium hysterophorus L.), apagafogo (Alternanthera ficoidea (L.) R. Br.) e guanxuma (Sida sp).

Os tratamentos testados incluiram herbicidas isolados (glyphosate, paraquat $\mathrm{e}$ MSMA) e a mistura pronta de glyphosate + 2,4-D amina combinados com $00,05,10,15,20,25$ e 30 dias de armazenamento, conforme o mostrado no Tabela 1. Manteve-se também uma testemunha, onde não se procedeu a aplicação de herbicidas.

Os herbicidas utilizados foram formulações comerciais de glyphosate (480 $\mathrm{g}$ do ingrediente ativo/l), mistura pronta de glyphosate + 2,4-D amina $(161,9+202,7 \mathrm{~g}$ do ingrediente ativo/l), MSMA (480 $\mathrm{g}$ do ingrediente ativo/l) e paraquat (200 g do ingrediente ativo/l).

Para o preparo das caldas, inicialmente foram rotulados recipientes plásticos de cinco litros (brancos e translúcidos), novos, com o nome de um herbicida e uma época de armazenamento.
Foram então realizadas as misturas das caldas de todos tratamentos rotulados com trinta dias e a data de aplicação foi pré-determinada para 30 dias após esta primeira mistura. Desta forma, a calda com 25 dias de armazenamento foi misturada cinco dias após a primeira e assim sucessivamente. Após a mistura, os recipientes foram fechados e armazenados à sombra, dentro de um galpão. Este método foi adotado visandose a aplicação de todos os tratamentos simultaneamente, evitando-se a possível interferência de fatores adversos com datas de aplicação diferentes.

Todas as caldas foram preparadas com uma água limpa, obtida de um poço profundo. $\mathrm{O}$ resultado da análise química desta água pode ser observado no Tabela 2.

A aplicação dos herbicidas foi realizada em 06 de janeiro de 1992, de forma dirigida, em pós-emergência tardia das plantas daninhas (altura variando entre 40 e $60 \mathrm{~cm}$ ). Utilizou-se um pulverizador costal, à pressão constante (mantida por $\mathrm{CO}_{2}$ comprimido) de $40 \mathrm{lbf} / \mathrm{pol}^{2} \quad(2,81$ $\mathrm{kg} / \mathrm{cm}^{2}$ ), equipado com barra de $2,0 \mathrm{~m}$ de largura e quatro bicos ${ }^{5}$ de jato plano ("leque"). Consumiuse o equivalente a 3001 de calda por ha.

Por ocasião da aplicação, a temperatura ambiente era de $28^{\circ} \mathrm{C}$ à sombra, a insolação era alta, o solo úmido na superfície e a velocidade do vento variou entre 1 e $3 \mathrm{~km} / \mathrm{h}$. A aplicação iniciouse às 12:00 hs e estendeu-se até às 15:08 horas.

Foram realizadas avaliações visuais de controle geral e por espécie das plantas daninhas presentes na área, aos 15, 31 e 46 dias após a aplicação, utilizando-se a escala de notas da ALAM (1974), onde a nota 01 representa 0 a $40 \%$ de controle e a nota 06 , de 91 a $100 \%$ de controle.

A análise estatística dos dados obedeceu ao esquema de parcelas subdivididas no tempo onde as subparcelas foram as 3 épocas de avaliações consideradas.

\section{RESULTADOS E DISCUSSÃO}

As médias dos resultados das avaliações visuais de controle por espécie de planta daninha e

\footnotetext{
${ }^{5}$ Albuz vermelho.
} 
as médias das notas de controle geral, para cada um dos períodos de armazenamento testados e para os vários herbicidas nas três épocas de avaliação, são mostrados nas Tabelas 3 a 6 . A análise de variância para as notas gerais de controle dos quatro herbicidas testados, nas três épocas de avaliação, é mostrada na Tabela 7.

TABELA 1. Dosagens dos herbicidas aplicados em pós-emergência e os diferentes períodos de armazenamento da calda pronta. Jaboticabal - SP, 1992.

\begin{tabular}{|c|c|c|c|}
\hline $\mathrm{N}^{\mathrm{o}}$ & $\begin{array}{l}\text { Herbicidas e } \\
\text { Testemunha }\end{array}$ & $\begin{array}{c}\text { Dosagens } \\
\text { (kg i.a./ha) }\end{array}$ & $\begin{array}{c}\text { Períodos de } \\
\text { Armazenamento da Calda } \\
\text { Pronta } \\
\text { (dias) }\end{array}$ \\
\hline 01 & glyphosate $^{(a)}$ & 1,44 & 00 \\
\hline 02 & glyphosate & 1,44 & 05 \\
\hline 03 & glyphosate & 1,44 & 10 \\
\hline 04 & glyphosate & 1,44 & 15 \\
\hline 05 & glyphosate & 1,44 & 20 \\
\hline 06 & glyphosate & 1,44 & 25 \\
\hline 07 & glyphosate & 1,44 & 30 \\
\hline 08 & glyphosate + 2,4-D & $0,81+1,01$ & 00 \\
\hline 09 & glyphosate + 2,4-D & $0,81+1,01$ & 05 \\
\hline 10 & glyphosate $+2,4-\mathrm{D}$ & $0,81+1,01$ & 10 \\
\hline 11 & glyphosate $+2,4-\mathrm{D}$ & $0,81+1,01$ & 15 \\
\hline 12 & glyphosate $+2,4-\mathrm{D}$ & $0,81+1,01$ & 20 \\
\hline 13 & glyphosate $+2,4-\mathrm{D}$ & $0,81+1,01$ & 25 \\
\hline 14 & glyphosate $+2,4-\mathrm{D}$ & $0,81+1,01$ & 30 \\
\hline 15 & MSMA $^{(\mathrm{c})}$ & 1,92 & 00 \\
\hline 16 & MSMA & 1,92 & 05 \\
\hline 17 & MSMA & 1,92 & 10 \\
\hline 18 & MSMA & 1,92 & 15 \\
\hline 19 & MSMA & 1,92 & 20 \\
\hline 20 & MSMA & 1,92 & 25 \\
\hline 21 & MSMA & 1,92 & 30 \\
\hline 22 & paraquat $^{(\mathrm{d})}$ & 0,60 & 00 \\
\hline 23 & paraquat & 0,60 & 05 \\
\hline 24 & paraquat & 0,60 & 10 \\
\hline 25 & paraquat & 0,60 & 15 \\
\hline 26 & paraquat & 0,60 & 20 \\
\hline 27 & paraquat & 0,60 & 25 \\
\hline 28 & paraquat & 0,60 & 30 \\
\hline 29 & testemunha sem herbicida & - & - \\
\hline
\end{tabular}

(a) Roundup SAqC (b) Command (c) Daconate (d) Gramoxone 200

TABELA 2. Teor de alguns elementos químicos e pH da água utilizada no preparo das caldas. Jaboticabal - SP,

\begin{tabular}{|c|c|c|c|c|c|}
\hline \multirow[t]{2}{*}{$\mathrm{Ph}$} & $\mathrm{K}$ & $\mathrm{Ca}$ & $\mathrm{Mg}$ & $\mathrm{S}$ & $\mathrm{Na}$ \\
\hline & \multicolumn{5}{|c|}{ ppm } \\
\hline \multirow[t]{3}{*}{7,30} & 1,90 & 4,00 & 0,72 & 0,48 & 14,80 \\
\hline & $\mathrm{Cl}$ & $\mathrm{Fe}$ & $\mathrm{Mn}$ & $\mathrm{Cu}$ & $\mathrm{Zn}$ \\
\hline & 0,50 & 0,01 & $\begin{array}{l}\text { ppm } \\
0,01\end{array}$ & 0,01 & 0,03 \\
\hline
\end{tabular}


TABELA 3. Médias das avaliações visuais, por espécie, e média das notas de controle geral, para o glifosato (0,72 kg/ha) aplicado após diferentes períodos de armazenamento da calda. Jaboticabal - SP, 1992.

\begin{tabular}{|c|c|c|c|c|c|c|c|c|c|c|c|c|c|c|c|c|c|c|c|c|c|}
\hline \multirow{4}{*}{$\begin{array}{c}\text { Plantas } \\
\text { Daninhas }\end{array}$} & \multicolumn{21}{|c|}{ ÉPOCAS DE AVALIAÇÃO (D.A.A.) } \\
\hline & \multicolumn{7}{|c|}{15} & \multicolumn{7}{|c|}{31} & \multicolumn{7}{|c|}{46} \\
\hline & \multicolumn{7}{|c|}{$\begin{array}{l}\text { Períodos de Armazenamento da Calda } \\
\text { (Dias) }^{(1)}\end{array}$} & \multicolumn{7}{|c|}{$\begin{array}{l}\text { Períodos de Armazenamento da Calda } \\
{\text { (Dias) }{ }^{(1)}}\end{array}$} & \multicolumn{7}{|c|}{$\begin{array}{l}\text { Períodos de Armazenamento da Calda } \\
{\text { (Dias) })^{(1)}}\end{array}$} \\
\hline & 00 & 05 & 10 & 15 & 20 & 25 & 30 & 00 & 05 & 10 & 15 & 20 & 25 & 30 & 00 & 05 & 10 & 15 & 20 & 25 & 30 \\
\hline $\begin{array}{l}\text { Capim- } \\
\text { colonião }\end{array}$ & $3,7^{2}$ & 4,8 & 4,5 & 5,0 & 4,8 & 4,5 & 4,5 & 5,8 & 5,8 & 5,7 & 6,0 & 5,8 & 6,0 & 5,8 & 6,0 & 6,0 & 6,0 & 6,0 & 6,0 & 6,0 & 6,0 \\
\hline $\begin{array}{l}\text { Capim- } \\
\text { marmelada }\end{array}$ & 5,5 & 5,5 & 5,7 & 5,8 & 5,8 & 5,8 & 5,7 & 6,0 & 6,0 & 6,0 & 6,0 & 6,0 & 6,0 & 6,0 & 6,0 & 6,0 & 6,0 & 6,0 & 6,0 & 6,0 & 6,0 \\
\hline $\begin{array}{l}\text { Capim- } \\
\text { amargoso }\end{array}$ & 5,5 & 5,5 & 5,7 & 5,8 & 5,8 & 5,8 & 5,5 & 6,0 & 6,0 & 6,0 & 6,0 & 6,0 & 6,0 & 6,0 & 6,0 & 6,0 & 6,0 & 6,0 & 6,0 & 6,0 & 6,0 \\
\hline Losna-branca & 4,8 & 5,0 & 5,0 & 5,8 & 5,0 & 5,3 & 5,2 & 6,0 & 6,0 & 6,0 & 6,0 & 6,0 & 6,0 & 6,0 & 6,0 & 6,0 & 6,0 & 6,0 & 6,0 & 6,0 & 6,0 \\
\hline Apaga-fogo & 5,0 & 4,3 & 5,0 & 5,8 & 5,0 & 4,7 & 4,7 & 6,0 & 6,0 & 6,0 & 6,0 & 6,0 & 6,0 & 6,0 & 6,0 & 6,0 & 6,0 & 6,0 & 6,0 & 6,0 & 6,0 \\
\hline Guanxuma & 5,0 & 4,7 & 5,0 & 5,8 & 5,0 & 4,7 & 5,5 & 6,0 & 6,0 & 6,0 & 6,0 & 6,0 & 6,0 & 6,0 & 6,0 & 6,0 & 6,0 & 6,0 & 6,0 & 6,0 & 6,0 \\
\hline Geral & 5,3 & 5,5 & 5,3 & 5,5 & 5,3 & 5,5 & 5,3 & 6,0 & 6,0 & 6,0 & 6,0 & 6,0 & 6,0 & 5,8 & 6,0 & 6,0 & 6,0 & 6,0 & 6,0 & 6,0 & 5,8 \\
\hline
\end{tabular}

D.A.A. - Dias Após a Aplicação

(1) Intervalo de tempo decorrido entre o preparo e a aplicação da calda

(2) Escala da ALAM (1974) 
TABELA 4. Médias das avaliações visuais, por espécie, e média das notas de controle geral, para a mistura pronta de glifosato + 2,4-D amina $(0,97+1,22 \mathrm{~kg} / \mathrm{ha})$ aplicado após diferentes períodos de armazenamento da calda. Jaboticabal - SP, 1992.

\begin{tabular}{|c|c|c|c|c|c|c|c|c|c|c|c|c|c|c|c|c|c|c|c|c|c|}
\hline \multirow{4}{*}{$\begin{array}{c}\text { Plantas } \\
\text { Daninhas }\end{array}$} & \multicolumn{21}{|c|}{ ÉPOCAS DE AVALIAÇÃO (D.A.A.) } \\
\hline & \multicolumn{7}{|c|}{15} & \multicolumn{7}{|c|}{31} & \multicolumn{7}{|c|}{46} \\
\hline & \multicolumn{7}{|c|}{$\begin{array}{l}\text { Períodos de Armazenamento da Calda } \\
\text { (Dias) }{ }^{(1)}\end{array}$} & \multicolumn{7}{|c|}{$\begin{array}{l}\text { Períodos de Armazenamento da Calda } \\
\text { (Dias) }^{(1)}\end{array}$} & \multicolumn{7}{|c|}{ 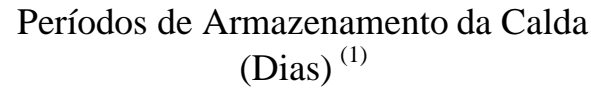 } \\
\hline & 00 & 05 & 10 & 15 & 20 & 25 & 30 & 00 & 05 & 10 & 15 & 20 & 25 & 30 & 00 & 05 & 10 & 15 & 20 & 25 & 30 \\
\hline $\begin{array}{l}\text { Capim- } \\
\text { colonião }\end{array}$ & $4,0^{2}$ & 2,5 & 2,5 & 2,5 & 2,3 & 2,0 & 2,0 & 6,0 & 4,3 & 5,7 & 5,2 & 5,3 & 4,0 & 5,5 & 6,0 & 5,0 & 5,8 & 5,7 & 5,8 & 4,7 & 5,8 \\
\hline $\begin{array}{l}\text { Capim- } \\
\text { marmelada }\end{array}$ & 4,3 & 4,2 & 4,3 & 4,8 & 4,8 & 4,8 & 4,3 & 6,0 & 6,0 & 6,0 & 6,0 & 6,0 & 5,7 & 6,0 & 6,0 & 6,0 & 6,0 & 6,0 & 6,0 & 5,7 & 6,0 \\
\hline $\begin{array}{l}\text { Capim- } \\
\text { amargoso }\end{array}$ & 2,0 & 2,3 & 2,2 & 2,0 & 2,0 & 2,0 & 2,0 & 6,0 & 6,0 & 6,0 & 6,0 & 6,0 & 6,0 & 6,0 & 6,0 & 6,0 & 6,0 & 6,0 & 6,0 & 6,0 & 6,0 \\
\hline Losna-branca & 3,7 & 3,0 & 4,0 & 3,8 & 2,5 & 3,0 & 3,3 & 6,0 & 6,0 & 6,0 & 6,0 & 6,0 & 6,0 & 6,0 & 6,0 & 6,0 & 6,0 & 6,0 & 6,0 & 6,0 & 6,0 \\
\hline Apaga-fogo & 3,7 & 3,5 & 5,0 & 5,0 & 4,3 & 4,0 & 4,5 & 6,0 & 6,0 & 6,0 & 6,0 & 6,0 & 6,0 & 6,0 & 6,0 & 6,0 & 6,0 & 6,0 & 6,0 & 6,0 & 6,0 \\
\hline Guanxuma & 2,3 & 1,8 & 2,2 & 3,2 & 2,2 & 2,0 & 2,0 & 6,0 & 6,0 & 6,0 & 5,2 & 6,0 & 6,0 & 5,8 & 6,0 & 6,0 & 6,0 & 5,2 & 6,0 & 6,0 & 6,0 \\
\hline Geral & 4,3 & 3,7 & 4,0 & 3,3 & 3,7 & 2,5 & 3,2 & 6,0 & 5,3 & 5,8 & 5,7 & 5,8 & 5,5 & 5,7 & 6,0 & 5,7 & 5,8 & 5,8 & 5,8 & 5,5 & 6,0 \\
\hline
\end{tabular}

D.A.A. - Dias Após a Aplicação

(1) Intervalo de tempo decorrido entre o preparo e a aplicação da calda

(2) Escala da ALAM (1974). 
TABELA 5. Médias das avaliações visuais, por espécie, e média das notas de controle geral, para o paraquato $(0,60 \mathrm{~kg} / \mathrm{ha})$ aplicado após diferentes períodos de armazenamento da calda. Jaboticabal - SP, 1992.

\begin{tabular}{|c|c|c|c|c|c|c|c|c|c|c|c|c|c|c|c|c|c|c|c|c|c|}
\hline \multirow{4}{*}{$\begin{array}{c}\text { Plantas } \\
\text { Daninhas }\end{array}$} & \multicolumn{21}{|c|}{ ÉPOCAS DE AVALIAÇÃO (D.A.A.) } \\
\hline & \multicolumn{7}{|c|}{15} & \multicolumn{7}{|c|}{31} & \multicolumn{7}{|c|}{46} \\
\hline & \multicolumn{7}{|c|}{$\begin{array}{l}\text { Períodos de Armazenamento da Calda } \\
\text { (Dias) }^{(1)}\end{array}$} & \multicolumn{7}{|c|}{$\begin{array}{l}\text { Períodos de Armazenamento da Calda } \\
\text { (Dias) }^{(1)}\end{array}$} & \multicolumn{7}{|c|}{$\begin{array}{l}\text { Períodos de Armazenamento da Calda } \\
\qquad{\text { (Dias) })^{(1)}}^{\text {a }}\end{array}$} \\
\hline & 00 & 05 & 10 & 15 & 20 & 25 & 30 & 00 & 05 & 10 & 15 & 20 & 25 & 30 & 00 & 05 & 10 & 15 & 20 & 25 & 30 \\
\hline $\begin{array}{l}\text { Capim- } \\
\text { colonião }\end{array}$ & $2,0^{2}$ & 1,8 & 2,0 & 1,8 & 1,3 & 1,3 & 1,3 & 1,2 & 1,0 & 1,3 & 1,3 & 1,2 & 1,2 & 1,0 & 1,0 & 1,0 & 1,0 & 1,0 & 1,0 & 1,0 & 1,0 \\
\hline $\begin{array}{l}\text { Capim- } \\
\text { marmelada }\end{array}$ & 3,3 & 2,7 & 3,2 & 3,7 & 4,0 & 5,0 & 2,0 & 2,2 & 1,3 & 1,5 & 2,8 & 3,5 & 2,7 & 1,3 & 1,2 & 1,0 & 1,0 & 1,5 & 1,2 & 2,5 & 1,0 \\
\hline $\begin{array}{l}\text { Capim- } \\
\text { amargoso }\end{array}$ & 1,8 & 1,8 & 1,7 & 1,7 & 1,0 & 1,2 & 1,3 & 1,0 & 1,0 & 1,0 & 1,0 & 1,0 & 1,0 & 1,0 & 1,0 & 1,0 & 1,0 & 1,0 & 1,0 & 1,0 & 1,0 \\
\hline Losna-branca & 1,2 & 1,0 & 1,0 & 1,0 & 1,7 & 2,7 & 1,8 & 1,0 & 1,0 & 1,0 & 1,0 & 1,0 & 2,8 & 3,3 & 1,0 & 1,0 & 1,0 & 1,0 & 1,0 & 2,7 & 1,5 \\
\hline Apaga-fogo & 1,7 & 1,8 & 1,3 & 1,5 & 1,0 & 1,0 & 2,0 & 1,0 & 1,0 & 1,0 & 1,0 & 1,0 & 1,0 & 1,0 & 1,0 & 1,0 & 1,0 & 1,0 & 1,0 & 1,0 & 1,0 \\
\hline Guanxuma & 3,5 & 3,2 & 4,5 & 4,3 & 2,8 & 2,8 & 2,8 & 4,0 & 2,8 & 4,0 & 1,0 & 1,0 & 1,0 & 1,0 & 4,0 & 2,7 & 4,0 & 1,0 & 1,0 & 1,0 & 1,0 \\
\hline Geral & 1,8 & 1,5 & 1,7 & 1,8 & 1,7 & 1,7 & 1,7 & 1,2 & 1,0 & 1,2 & 1,3 & 1,3 & 1,2 & 1,0 & 1,0 & 1,0 & 1,0 & 1,0 & 1,0 & 1,0 & 1,0 \\
\hline
\end{tabular}

D.A.A. - Dias Após a Aplicação

(1) Intervalo de tempo decorrido entre o preparo e a aplicação da calda

(2) Escala da ALAM (1974). 
TABELA 6. Médias das avaliações visuais, por espécie, e média das notas de controle geral, para o MSMA (2,40 kg/ha) aplicado após diferentes períodos de armazenamento da calda. Jaboticabal - SP, 1992.

\begin{tabular}{|c|c|c|c|c|c|c|c|c|c|c|c|c|c|c|c|c|c|c|c|c|c|}
\hline \multirow{4}{*}{$\begin{array}{c}\text { Plantas } \\
\text { Daninhas }\end{array}$} & \multicolumn{21}{|c|}{ ÉPOCAS DE AVALIAÇÃO (D.A.A.) } \\
\hline & \multicolumn{7}{|c|}{15} & \multicolumn{7}{|c|}{31} & \multicolumn{7}{|c|}{46} \\
\hline & \multicolumn{7}{|c|}{$\begin{array}{l}\text { Períodos de Armazenamento da Calda } \\
\text { (Dias) }^{(1)}\end{array}$} & \multicolumn{7}{|c|}{$\begin{array}{l}\text { Períodos de Armazenamento da Calda } \\
{\text { (Dias })^{(1)}}\end{array}$} & \multicolumn{7}{|c|}{$\begin{array}{l}\text { Períodos de Armazenamento da Cald } \\
\text { (Dias) }^{(1)}\end{array}$} \\
\hline & 00 & 05 & 10 & 15 & 20 & 25 & 30 & 00 & 05 & 10 & 15 & 20 & 25 & 30 & 00 & 05 & 10 & 15 & 20 & 25 & 30 \\
\hline $\begin{array}{l}\text { Capim- } \\
\text { colonião }\end{array}$ & $2,7^{2}$ & 1,7 & 1,8 & 2,0 & 2,0 & 1,5 & 1,7 & 2,5 & 1,5 & 2,0 & 1,8 & 2,0 & 1,5 & 1,3 & 1,5 & 1,0 & 1,0 & 1,0 & 1,2 & 1,0 & 1,0 \\
\hline $\begin{array}{l}\text { Capim- } \\
\text { marmelada }\end{array}$ & 1,5 & 1,5 & 1,5 & 1,5 & 1,5 & 1,5 & 1,5 & 1,7 & 1,8 & 1,5 & 1,2 & 1,7 & 1,2 & 1,5 & 1,3 & 1,5 & 1,3 & 1,2 & 1,3 & 1,0 & 1,2 \\
\hline $\begin{array}{l}\text { Capim- } \\
\text { amargoso }\end{array}$ & 1,5 & 1,2 & 1,2 & 1,2 & 1,3 & 1,3 & 1,3 & 1,3 & 1,2 & 1,3 & 1,0 & 1,0 & 1,0 & 1,0 & 1,3 & 1,0 & 1,0 & 1,0 & 1,0 & 1,0 & 1,0 \\
\hline Losna-branca & 1,8 & 3,3 & 2,7 & 2,2 & 2,2 & 1,8 & 1,8 & 6,0 & 5,5 & 6,0 & 4,3 & 6,0 & 4,3 & 3,2 & 4,3 & 5,0 & 6,0 & 2,7 & 6,0 & 6,0 & 4,3 \\
\hline Apaga-fogo & 1,0 & 1,0 & 1,0 & 1,0 & 1,2 & 1,2 & 1,0 & 1,0 & 1,0 & 1,0 & 1,0 & 1,0 & 1,0 & 1,0 & 1,0 & 1,0 & 1,0 & 1,0 & 1,0 & 1,0 & 1,0 \\
\hline Guanxuma & 1,0 & 1,0 & 1,0 & 1,0 & 1,2 & 1,0 & 1,0 & 1,0 & 1,0 & 1,0 & 1,0 & 1,0 & 1,0 & 1,0 & 1,0 & 1,0 & 1,0 & 1,0 & 1,0 & 1,0 & 1,0 \\
\hline Geral & 1,7 & 1,8 & 1,7 & 2,0 & 1,7 & 1,5 & 1,5 & 1,5 & 1,7 & 1,7 & 1,7 & 1,7 & 1,3 & 1,5 & 1,2 & 1,2 & 1,0 & 1,0 & 1,0 & 1,0 & 1,0 \\
\hline
\end{tabular}

D.A.A. - Dias Após a Aplicação

(1) Intervalo de tempo decorrido entre o preparo e a aplicação da calda

(2) Escala da ALAM (1974). 
TABELA 7. Análise de variância das avaliações visuais de controle (nota geral) para os vários herbicidas, períodos de armazenamento e épocas de avaliação. Jaboticabal - SP, 1992.

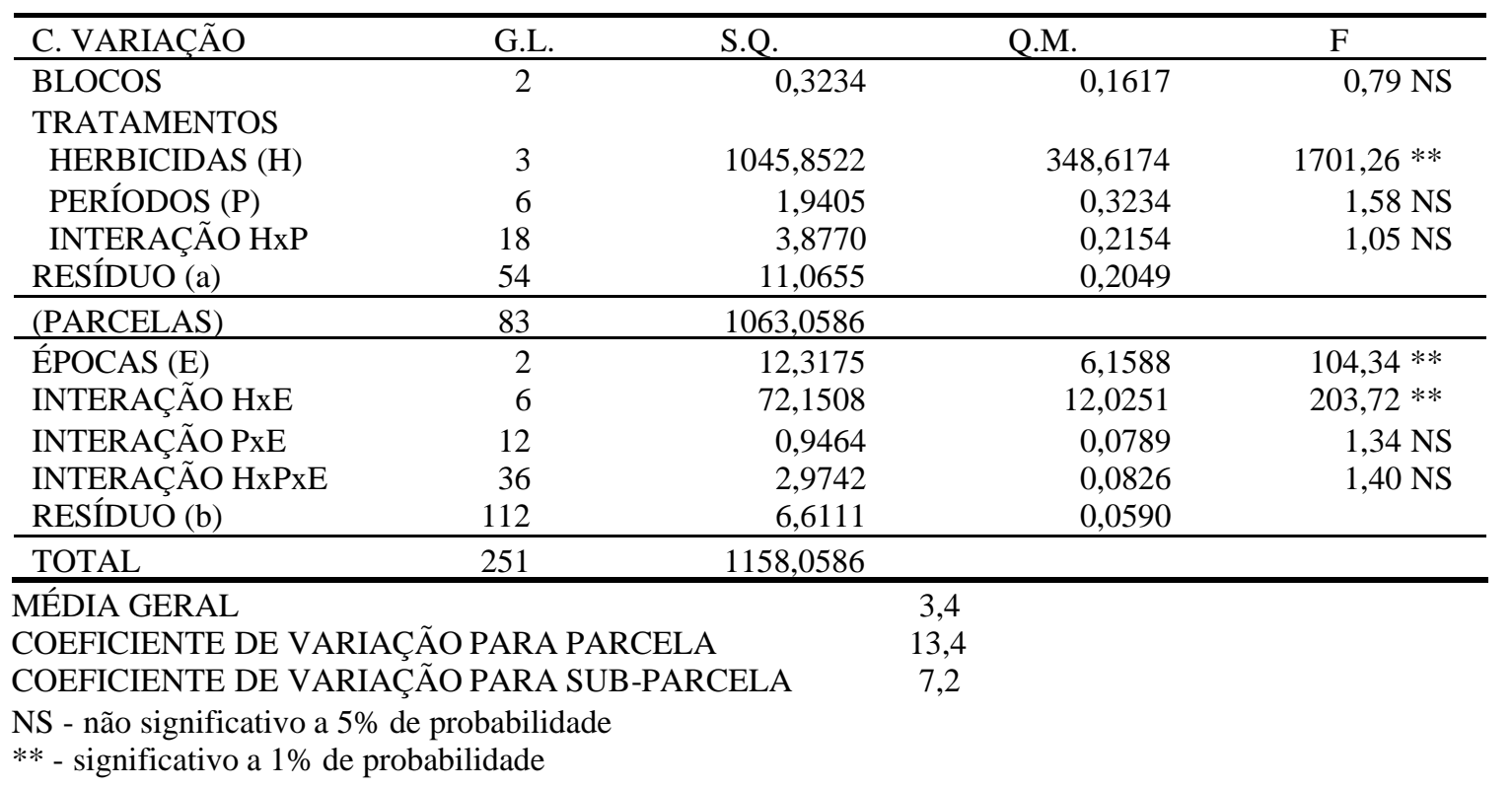

Através da análise da Tabela 7 observa-se que apenas para herbicidas e épocas de avaliação apareceram diferenças significativas em relação ao controle das plantas daninhas. Verifica-se também que a interação herbicidas $\mathrm{x}$ épocas também foi significativa, indicando existir dependência entre os efeitos destes fatores. No entanto, os períodos de armazenamento testados apresentam efeitos semelhantes sobre o controle, não influenciando na eficiência dos herbicidas utilizados, nas diferentes épocas de avaliação.

Aplicando-se o teste de Tukey, ao nível de $5 \%$ de probalilidade, à interação herbicidas $\mathrm{x}$ épocas de avaliação (Tabela 8), observa-se que o controle das plantas daninhas com a mistura comercial de glyphosate +2,4-D amina e com o glyphosate isolado evoluiu desde a aplicação até 31 D.A.A. tendo se mantido até 46 D.A.A. Este resultado era esperado devido a ação sistêmica destes herbicidas. O paraquat e o MSMA, no entanto, apresentaram controle máximo aos $15 \mathrm{e}$ 31 D.A.A. respectivamente, tendo declinado após esta época. Este comportamento também pode ser explicado pelo modo de ação destes herbicidas, que agem basicamente nas células próximas à região do contato, sem ação sistêmica. Verifica-se ainda que a partir dos 31 D.A.A. os controles obtidos pela mistura se igualaram ao do glyphosate isolado, e se mantiveram até os 46 D.A.A. Estes tratamentos herbicidas foram sempre superiores ao MSMA e ao paraquat.

\section{AGRADECIMENTOS}

Os autores agradecem à MONSANTO DO BRASIL - DIVISÃO AGRICULTURA, pelo empenho no auxílio à busca de bibliografias sobre os assuntos estudados, tão escassas nas bibliotecas brasileiras. 
TABELA 8. Teste de Tukey aplicado às médias de controle, para a interação herbicidas $x$ épocas de avaliação.

\begin{tabular}{lcccccccccc}
\hline \multicolumn{1}{c}{ HERBICIDAS $^{(1)}$} & \multicolumn{1}{c}{ ÉPOCAS (D.A.A.) } \\
\cline { 2 - 9 } & & b & 5,4 & A & a & 6,0 & A & a & 6,0 & A \\
\hline glyphosate $(1,44)$ & b & 3,5 & B & a & 5,7 & A & a & 5,8 & A \\
glyphosate $+2,4-D(0,81+1,01)$ & a & 1,7 & C & a & 1,6 & B & b & 1,0 & B \\
MSMA $(1,92)$ & a & 1,7 & C & b & 1,2 & B & b & 1,0 & B \\
paraquat $(0,60)$ & & & & & & & & &
\end{tabular}

(1) Dosagens em kg i.a./ha

D.A.A. - Dias Após a Aplicação

DMS(TUKEY) (H d. E) $=0,7$

DMS(TUKEY) (E d. H) $=0,5$

Médias seguidas por uma mesma letra maiúscula não diferem entre si numa mesma coluna, pelo teste de Tukey a $5 \%$ de probabilidade

Médias antecedidas por uma mesma letra minúscula não diferem entre si numa mesma linha, pelo teste de Tukey a 5\% de probabilidade.

\section{LITERATURA CITADA}

ALAM (Asóciacion Latinoamericana de Malezas). Recomendaciones sobre unificación de los sistemas de evaluación en ensayos de control de malezas. ALAM, Bogotá, v. 1, n. 1, p. 35-38, 1974.

ALMEIDA, S.F., RODRIGUES, B.N. Guia do herbicida: contribuição para 0 uso adequado e plantio direto e convencional. Londrina: IAPAR, 1985. 482p.

BOWMER, K.H., BOULTON, P.M.D., SHORT, D.L., HIGGINS, M.L. Glyphosatesediment interactions and phytotoxicity in turbid water. Pestic. Sci., v. 17, n. 2, p. 79 88, 1986.

BRØNSTAD, J.O., FRIESTAD, H.O. Behaviour of glyphosate in the aquatic environment. In: GROSSBARD,E, ATKINSON, D. The herbicide gliphosate. New York: Butterworth \& Co (Publishers) Ltd, 1985. p. 200-205.
LUND-HØIE, K., FRIESTAD, H.O. Photodegradation of the herbicide glyphosate in water. Bull. Environ. Contam. Toxicol., v. 36, n. 5, p. 723-729, 1986.

MATUO, T. Técnicas de aplicação de defensivos. In: FERREIRA, M.E. Energia na Agricultura, Jaboticabal, FUNEP, 1985. p. 113-130.

OZEKI, Y., KUNZ, R., RESENDE, P. Gesapax \& tecnologia: avaliação e sugestões para aumento de rendimento operacional dos pulverizadores. São Paulo: Ciba-Geigy, s/d. 8p.

RUEPPEL, M.L., BRIGHTWELL, B.B., SCHAEFER, J., MARVEL, J.T. Metabolism and degradation of glyphosate in soil and water. J. Agric. Food Chem., v. 25, n. 3, p. 517-528, 1997. 